Received: 2016.01.17 Accepted: 2016.02.22 Published: 2016.06 .14

\title{
Hepatitis B Vaccination in End-Stage Pulmonary Disease Patients Evaluated for Lung Transplantation: A Retrospective Single-Center Evaluation
}

Authors' Contribution: Study Design A Data Collection B Statistical Analysis C Data Interpretation D Manuscript Preparation E Literature Search F Funds Collection G
ABCDEF 1 Alexandra Wald*

ABCDEF 1 Lea Deterding*

ABCDEF 2 Melanie Maier

ABCDEF 2 Uwe G. Liebert

ABCDEF 3 Thomas Berg

ABCDEF 1 Hubert Wirtz

ABCDEF 3 Johannes Wiegand
1 Department of Pneumology, University of Leipzig, Leipzig, Germany 2 Institute of Virology, University of Leipzig, Leipzig, Germany

3 Department of Gastroenterology and Rheumatology, University of Leipzig, Leipzig, Germany
Corresponding Author: Source of support:

* Shared first co-authorship

Johannes Wiegand, e-mail: johannes.wiegand@medizin.uni-leipzig.de

German Research Foundation (DFG) and Universität Leipzig within the program of Open Access Publishing. AW + JW received an unrestricted research grant from GlaxoSmithKline (GSK vaccines)

Background: In times of limited organs for transplantation, anti-HBc-positive organs can be accepted for lung transplantation to increase the number of donors. Transplant recipients should be vaccinated against hepatitis $B$ to prevent HBV infection. However, response after HBV vaccination has only been poorly evaluated in patients with end-stage pulmonary disease.

Material/Methods: Anti-HBs titers of 40 anti-HBc negative patients with end-stage pulmonary disease evaluated for lung transplantation were analyzed with the Architect ${ }^{\circledast}$ system (Abbott, Germany). Responders, partial responders, or non-responders after HBV vaccination were defined by anti-HBs titers $>100 \mathrm{IU} / \mathrm{L}, 10-100 \mathrm{IU} / \mathrm{L}$, and $<10 \mathrm{IU} / \mathrm{L}$, respectively.

Results: $\quad$ There were 34/40 individuals (85\%) vaccinated against hepatitis B, and 6 were not vaccinated. Response, partial response, and non-response after vaccination were observed in 10/34 (29.4\%), 11/34 (32.4\%), and 13/34 $(38.2 \%)$ of patients, respectively. Response to vaccination did not correlate with sex, pulmonary disease, comorbidities, immunosuppressive therapy, or smoking status.

Conclusions: $\quad$ Although $85 \%$ of patients evaluated for lung transplantation were vaccinated against hepatitis $\mathrm{B}, 38.2 \%$ did not show an anti-HBs titer $>10 \mathrm{IU} / \mathrm{L}$. Thus, anti-HBs titers should be regularly monitored. Nonresponders should be considered for booster vaccinations, alternative vaccination schedules, or prophylactic treatment with a nucleos(t)ide analogue in case of transplantation of an anti-HBc-positive organ.

MeSH Keywords: Disease Transmission, Infectious • Heart-Lung Transplantation • Hepatitis B Vaccines • Lamivudine

Full-text PDF: http://www.annalsoftransplantation.com/abstract/index/idArt/897624

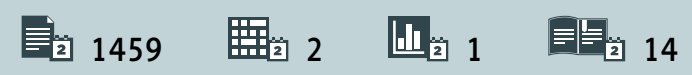




\section{Background}

In times of limited donor resources for any solid organ transplantation, including lung transplantation for end-stage pulmonary disease, there is a mismatch between the number of transplant candidates and the number of available organs. One option to narrow this gap is to accept organs from anti-HBcpositive donors to increase the number of available organs. Anti-HBc-positive individuals account for up to $15-20 \%$ of all potential donors; therefore, inclusion of this population results in a substantial increase of potential donor organs [1,2]. Survival of recipients of anti-HBc-positive lung transplants is not impaired compared to recipients of anti-HBc-negative organs [3]; however, there is a risk of acquiring chronic hepatitis $B$ virus (HBV) infection after transplantation [4].

An effective strategy to prevent $\mathrm{HBV}$ transmission is vaccination of the anti-HBc-negative transplant recipient. Hepatitis $B$ vaccination with recombinant $\mathrm{HBsAg}$ should be performed when candidates are on the waiting list prior to transplantation because its efficacy will be limited thereafter due to necessary immunosuppression $[5,6]$. The standard vaccination course includes 3 intramuscular vaccinations at the time points zero, month 1 , and month 6 [7].

Unfortunately, systematic data from hepatitis B vaccination programs in patients wait-listed for lung transplantation are scarce. In a Spanish survey all transplant centers reported to perform hepatitis B vaccination, however, detailed data whether all three necessary vaccinations were completely administered or resulted in anti-HBs titers $>100 \mathrm{U} / \mathrm{L}$ were not published [2]. Monocentric data on 96 lung transplantation candidates described overall anti-HBs response rates of $54 \%$ after standard or accelerated vaccination schedules [5]. Alternatively, response rates may increase more after high-dose compared to standard-dose vaccination regimens [8]. Additionally, retrospective data on US heart transplant recipients indicate that only 13/29 patients achieved a sufficient anti-HBs titer after a standard intramuscular vaccination schedule with $10 \mu \mathrm{g}$ of recombinant $\mathrm{HBsAg}$ [9].

With respect to these limited data, the aim of the current study was to systematically characterize the hepatitis $B$ vaccination program and the resulting anti-HBs titers in patients wait-listed for lung transplantation at our transplant center.

\section{Material and Methods}

All individuals with end-stage pulmonary disease listed for lung transplantation at our hospital between May 2014 and February 2015 were consecutively evaluated. Vaccination status of anti-HBc-negative patients was retrospectively determined by vaccination cards. In Germany, these vaccination cards are paper booklets distributed during childhood to document any vaccination administered during the lifetime.

Hepatitis B vaccinations were performed intramuscularly with recombinant $\mathrm{HBsAg}$ with the licensed vaccines Engerix ${ }^{\circledast}(20 \mu \mathrm{g})$, Twinri $(20 \mu \mathrm{g})$, HBVAXpro ${ }^{\circledR}(10 \mu \mathrm{g})$, or GenH-B-Vax ${ }^{\circledR}(10 \mu \mathrm{g})$.

Anti-HBc and anti-HBs titers were analyzed with the Architect $\circledast$ system (Abbott, Wiesbaden, Germany). Responders, partial responders, or non-responders after HBV vaccination were defined by anti-HBs titers $>100 \mathrm{IU} / \mathrm{L}, 10-100 \mathrm{IU} / \mathrm{L}$, and $<10 \mathrm{IU} / \mathrm{L}$, respectively [7].

Concomitant medications were extracted from medical charts. Patients with ongoing prednisolone therapy (2.5-20 mg per day) or repetitive prednisolone bolus therapy (40-100 mg) were classified as "long-term prednisolone" treatment. Immunosuppressants other than prednisolone were not used.

Data analysis was performed using Excel (Microsoft, Redmond, WA, USA). Statistical differences were analyzed by Fisher's exact test (GraphPad Software, La Jolla, CA, USA). A p-value $<0.05$ was considered as statistically significant.

The project was evaluated and approved by the Ethics Committee of the University of Leipzig (ethics vote number 170-14-02062014). All patients provided written informed consent prior to any study-related procedures.

\section{Results}

\section{Baseline characteristics of the study population}

During the study period, 61 patients with end-stage pulmonary disease were evaluated or wait-listed for lung transplantation; 21 were excluded due to classification as non-transplant candidates $(n=9)$, positive anti-HBc titers $(n=2)$, death $(n=2)$, transplantation $(n=4)$, or incomplete data $(n=4)$. Thus, the study population consisted of 40 anti-HBc-negative patients $(50 \%$ female, age 57.2 \pm 9.9 years, COPD $n=24 / 40$, long-term prednisolone therapy $n=9 / 40$, history of smoking $n=30 / 40$ ). Further baseline characteristics are summarized in Table 1. Only 1 of the patients had clinically relevant liver disease, and this patient presented with compensated Child A cirrhosis due to alpha-1 antitrypsin deficiency.

Patients considered for further analysis did not significantly differ from excluded cases concerning, age, sex, etiology of end-stage pulmonary disease, long-term steroid therapy, or concomitant diseases. 
Table 1. Baseline characteristics of the study cohort.

\begin{tabular}{|c|c|c|c|c|c|c|c|c|c|c|c|c|c|}
\hline \multirow{2}{*}{$\begin{array}{l}\text { Baseline } \\
\text { characteristics } \\
\text { Women (\%) }\end{array}$} & \multicolumn{2}{|c|}{$\begin{array}{c}\text { Total } \\
\text { population } \\
n=40\end{array}$} & \multicolumn{2}{|c|}{$\begin{array}{c}\text { Non- } \\
\text { (Hepatitis B-) } \\
\text { vaccinated } \\
\text { population } \\
n=6\end{array}$} & \multicolumn{2}{|c|}{$\begin{array}{l}\text { (Hepatitis } B \text {-) } \\
\text { vaccinated } \\
\text { population } \\
n=34\end{array}$} & \multicolumn{2}{|c|}{$\begin{array}{l}\text { Responders } \\
\qquad \begin{array}{l}n=10 \\
(29.4 \%)\end{array}\end{array}$} & \multicolumn{2}{|c|}{$\begin{array}{l}\text { Partial } \\
\text { responders } \\
n=11 \\
(32.4 \%)\end{array}$} & \multicolumn{2}{|c|}{$\begin{array}{l}\text { Non- } \\
\text { responders } \\
n=13 \\
(38.2 \%)\end{array}$} & \multirow[t]{2}{*}{$\begin{array}{l}\text { P-Values } \\
\text { (correlation } \\
\text { with } \\
\text { response) }\end{array}$} \\
\hline & 20 & $(50.0)$ & 3 & $(50.0)$ & 17 & $(50.0)$ & 8 & $(80.0)$ & 2 & $(18.2)$ & 7 & $(53.8)$ & \\
\hline Men (\%) & 20 & $(50.0)$ & 3 & $(50.0)$ & 17 & $(50.0)$ & 2 & $(20.0)$ & 9 & $(81.8)$ & 6 & $(46.2)$ & \\
\hline Median age, years & 59.4 & 26-27) & 58.0( & 26-66) & 59.4 & 28-67) & 60.3 & $52-64)$ & 59.9 & 28-67) & 59.4 & 54-66) & \\
\hline Median BMI kg/m² & 23.0 & 15-37) & 23.0( & 19-27) & 23.0 & 15-37) & 22.5 & 15-27) & 23.0 & 19-37) & 24.0 & 21-33) & \\
\hline \multicolumn{14}{|c|}{ Number of hepatitis B vaccinations } \\
\hline Three or more (\%) & 24 & $(60.0)$ & 0 & $(0.0)$ & 24 & $(70.6)$ & 8 & $(80.0)$ & 8 & $(72.7)$ & 8 & $(61.5)$ & \\
\hline Two (\%) & 10 & $(25.0)$ & 0 & $(0.0)$ & 10 & $(29.4)$ & 2 & $(20.0)$ & 3 & $(27.3)$ & 5 & $(38.5)$ & \\
\hline None (\%) & 6 & (15.0) & 6 & $(100)$ & 0 & $(0.0)$ & 0 & $(0.0)$ & 0 & $(0.0)$ & 0 & $(0.0)$ & \\
\hline \multicolumn{14}{|l|}{ Lung disease } \\
\hline COPD (\%) & 24 & $(60.0)$ & 3 & $(50.0)$ & 21 & $(61.8)$ & 8 & $(80.0)$ & 4 & $(36.4)$ & 9 & $(69.2)$ & \multirow{2}{*}{0.2508} \\
\hline Non-COPD (\%) & 16 & $(40.0)$ & 3 & $(50.0)$ & 13 & $(38.2)$ & 2 & $(20.0)$ & 7 & $(63.3)$ & 4 & $(30.8)$ & \\
\hline \multicolumn{14}{|l|}{ Co-morbidities } \\
\hline Diabetes mellitus (\%) & 8 & $(20.0)$ & 3 & $(50.0)$ & 5 & $(14.7)$ & 0 & $(0.0)$ & 3 & $(27.3)$ & 2 & $(15.4)$ & 0.2908 \\
\hline $\begin{array}{l}\text { Renal Insufficiency (\%) } \\
\text { GFR }<90 \mathrm{mi} / \mathrm{min} / 1.73 \mathrm{~m}^{2}\end{array}$ & 20 & $(50.0)$ & 4 & $(66.6)$ & 16 & $(47.0)$ & 7 & $(70.0)$ & 4 & $(36.4)$ & 5 & $(38.5)$ & 0.1341 \\
\hline $\begin{array}{l}\text { Renal Insufficiency (\%) } \\
\text { GFR }<60 \text { ) } \\
\mathrm{mi} / \mathrm{min} / 1.73 \mathrm{~m}^{2}\end{array}$ & 2 & $(5.0)$ & 0 & $(0.0)$ & 2 & (5.8) & 0 & $(0.0)$ & 1 & (9.1) & 1 & (7.7) & 1.0000 \\
\hline \multicolumn{14}{|l|}{ Smoking status } \\
\hline Ex-smoker (\%) & 30 & $(75.0)$ & 3 & $(50.0)$ & 27 & $(79.4)$ & 7 & $(70.0)$ & 9 & $(81.8)$ & 11 & $(84.6)$ & \multirow{2}{*}{0.3943} \\
\hline Never-smoker (\%) & 10 & $(25.0)$ & 3 & $(50.0)$ & 7 & (20.6) & 3 & $(30.0)$ & 2 & $(18.2)$ & 2 & (15.4) & \\
\hline \multicolumn{14}{|c|}{ Long-term prednisolone therapy } \\
\hline Yes (\%) & 9 & $(25.0)$ & 3 & $(50.0)$ & 6 & (20.6) & 2 & (20.0) & 1 & (9.1) & 3 & (30.8) & \multirow{2}{*}{1.0000} \\
\hline No (\%) & 31 & $(75.0)$ & 3 & $(50.0)$ & 28 & $(79.4)$ & 8 & $(80.0)$ & 10 & $(90.9)$ & 10 & $(69.2)$ & \\
\hline
\end{tabular}

\section{Hepatitis B vaccination schedules}

Hepatitis B vaccination was performed in 34/40 (85\%) patients prior to wait-listing for lung transplantation. There were $6 / 40$ (15\%) individuals who were not vaccinated, and 10/34 (29.4\%) and $24 / 34(70.6 \%)$ of cases received 2 or 3 or more vaccinations, respectively. Baseline vaccination was performed with Engerix $^{\circledR}$, Twinrix $^{\circledR}$, HBVAXpro $^{\circledR}$, or GenH-B-Vax ${ }^{\circledR}$ in $15,15,1$, and 2 patients, respectively. One hepatitis vaccine could not be identified in the vaccination card. The median interval between the baseline vaccination and the 2 booster vaccinations was 5 (minimum 1, maximum 1125) weeks and 30 (minimum 3, maximum 363) weeks (Table 2). Four patients received more than 3 vaccinations (maximum 7 vaccinations during a time span of 15 years).

One patient received the baseline and first booster vaccination within 1 week as part of an accelerated vaccine schedule due to expected timely transplantation. Vaccinations with higher than the standard vaccine dose were not performed. Anti-HBs response was analyzed 36.5 (minimum 1, maximum $805)$ weeks after the last hepatitis $B$ vaccination. 
Table 2. Details of hepatitis B vaccination schedules.

\begin{tabular}{|c|c|c|c|c|}
\hline & Responder & Partial-responder & Non-responder & $\begin{array}{l}\text { Total hepatitis } \\
\text { B-vaccinated } \\
\text { population }\end{array}$ \\
\hline $\begin{array}{l}\text { Median age at baseline hepatitis B } \\
\text { vaccination (range) }\end{array}$ & $54.1(31 / 61)$ & $51.0(11 / 65)$ & $58.5(46 / 64)$ & $56.0(11 / 65)$ \\
\hline $\begin{array}{l}\text { Median time interval (in weeks) } \\
\text { between baseline vaccination } \\
\text { and anti-HBs titer determination } \\
\text { (range) }\end{array}$ & $131(21 / 1014)$ & $167(10 / 1200)$ & $47(2 / 404)$ & $51.5(2 / 1200)$ \\
\hline $\begin{array}{l}\text { Median time interval (in weeks) } \\
\text { between latest vaccination and } \\
\text { anti-HBs titer determination } \\
\text { (range) }\end{array}$ & $91(3 / 770)$ & $33.5(6 / 805)$ & $20(1 / 382)$ & $36.5(1 / 805)$ \\
\hline
\end{tabular}

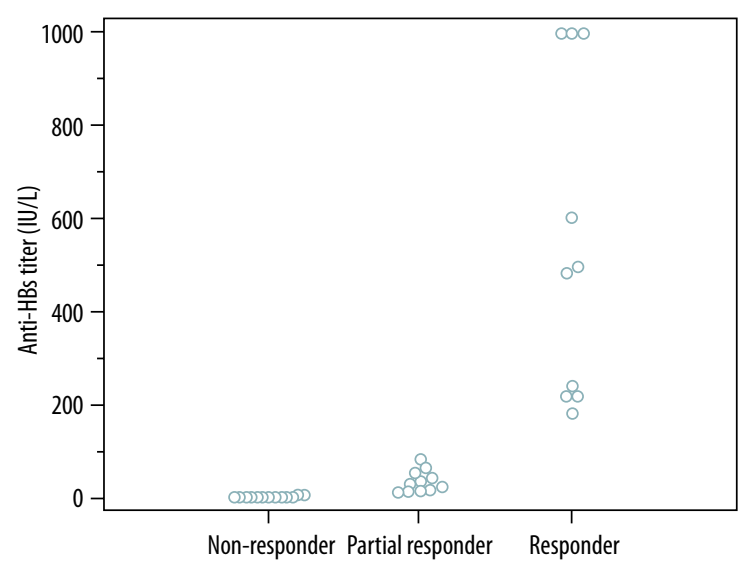

Figure 1. Individual anti-HBs titers in hepatitis B vaccination responders, partial responders, and non-responders.

\section{Efficacy of hepatitis B vaccination}

Anti-HBs titers of $>100 \mathrm{IU} / \mathrm{L}, 10-100 \mathrm{IU} / \mathrm{L}$, and $<10 \mathrm{IU} / \mathrm{L}$ were observed in 10/34 (29.4\%), 11/34 (32.4\%), and 13/34 (38.2\%) patients (Figure 1). Response to vaccination did not correlate with sex, pulmonary disease (COPD vs. non-COPD), long-term prednisolone therapy, smoking status, or co-morbidities. The age of responders, partial responders, or non-responders at the baseline vaccination did not differ significantly. The median time interval between the last hepatitis $B$ vaccination and the titer control was 20 weeks in non-responders and 91 weeks in responders.

\section{Discussion}

Hepatitis B vaccination is recommended in solid organ transplant candidates prior to surgery $[10,11]$, but existing data on hepatitis B vaccination programs in patients wait-listed for lung or heart transplantation are limited by small patient numbers, retrospective analysis, or single-center study design $[5,8,9]$.

In our cohort, hepatitis B vaccination was administered to $85 \%$ of patients. Spanish data report that all national transplant centers regularly vaccinate against hepatitis $B$ in patients on the waiting list for lung transplantation, although none quantify the level of anti-HBs titers [12]. However, quantification of anti-HBs titers is important, because $38.2 \%$ of our vaccinated study population did not reach anti-HBs titers $>10 \mathrm{IU} / \mathrm{L}$ while on the waiting list. Galar et al. reported overall anti-HBs response rates of $54.2 \%$ [5]. Unfortunately, they did not provide detailed anti-HBs titers, so their results are difficult to compare with our study.

Anti-HBs titers should be quantified 4-8 weeks after the third hepatitis $B$ vaccination of a standard vaccination course [7]. Unfortunately, due to our retrospective study design we did not have any data at this time point, but analyzed the time interval between the initial and the last administered hepatitis $B$ vaccination and the time point of the current study evaluation.

Reasons for impaired anti-HBs immunity after vaccination are numerous and include advanced age at initiation of the vaccination schedule, history of smoking, immunosuppression, male sex, and advanced end-stage pulmonary or heart disease $[5,9]$. Similar correlations were not observed in our study. These results should not be overinterpreted due to the limited number of patients and the single-center study design. In case of an anti-HBs titer $<10 \mathrm{IU} / \mathrm{L}$, a standardized treatment approach prior to transplantation has not been developed yet. It may be better to vaccinate with a combined hepatitis $A$ and $B$ vaccine (Twinrix ${ }^{\circledR}$ ) compared to the corresponding monovalent vaccines (Havrix ${ }^{\circledR}$ and Engerix- $\mathrm{B}^{\circledR}$ ) because this strategy might induce better anti-HBs responses [13]. In our cohort, an anti-HBs titer $>100 \mathrm{IU} / \mathrm{L}$ was achieved by $5 / 10$ vs. 2/10 individuals after 3 vaccinations with Twinrix ${ }^{\circledR}$ and Engerix ${ }^{\circledR}$, respectively. This 
difference was not statistically significant, but is again impaired by the small cohort size. Alternative treatment options include additional booster vaccinations [9], accelerated vaccination schedules [5], or high-dose booster vaccinations [8]. However, these alternatives have not been evaluated in large prospective controlled trials and reach sufficient anti-HBs titers in only about $50 \%$ of cases. In our cohort, 4 patients received more than 3 hepatitis $B$ vaccinations, and all developed an anti-HBs titer $>10 \mathrm{IU} / \mathrm{L}$. If booster vaccinations do not induce sufficient humoral immunity, prophylactic treatment with an HBV nucleos(t)ide analogue (e.g., lamivudine) may be another option to prevent hepatitis B infection after transplantation of an anti-HBc-positive organ [14].

\section{References:}

1. Salvadori M, Rosso G, Carta P et al: Donors positive for hepatitis B core antibodies in nonliver transplantations. Transplant Proc, 2011; 43(1): 277-79

2. Chamorro C, Aparicio M: Influence of anti-HBc positive organ donor in lung donor selection. Arch Bronconeumol, 2012; 48(9): 320-24

3. Hartwig MG, Patel V, Palmer SM et al: Hepatitis B core antibody positive donors as a safe and effective therapeutic option to increase available organs for lung transplantation. Transplantation, 2005; 80(3): 320-25

4. Dhillon GS, Levitt J, Mallidi $\mathrm{H}$ et al: Impact of hepatitis $\mathrm{B}$ core antibody positive donors in lung and heart-lung transplantation: An analysis of the United Network For Organ Sharing Database. Transplantation, 2009; 88(6): 842-46

5. Galar A, Engelson BA, Kubiak DW et al: Serologic response to hepatitis B vaccination among lung transplantation candidates. Transplantation, 2014; 98(6): 676-79

6. Fytili P, Ciesek S, Manns MP et al: Anti-HBc seroconversion after transplantation of anti-HBC positive nonliver organs to anti-HBc negative recipients. Transplantation, 2006; 81(5): 808-9

7. Robert Koch Institut. Empfehlungen der Ständigen Impfkommission (STIKO) am Robert Koch-Institut/Stand: August 2015. Epid Bull, 2015; 34: 327-62 [in German]

\section{Conclusions}

Although $85 \%$ of patients on the waiting list for lung transplantation were vaccinated against hepatitis B, 38.2\% did not present with an anti-HBs Titer $>10 \mathrm{IU} / \mathrm{L}$. Thus, titer controls after hepatitis $B$ vaccination should be regularly monitored. In case of insufficient immunity, patients should be considered for additional booster vaccinations, alternative vaccination schedules, or prophylactic treatment with a nucleos(t)ide analogue to prevent hepatitis $B$ infection in case of transplantation of an anti-HBc-positive donor organ.

8. Hayney MS, Welter DL, Reynolds AM et al: High-dose hepatitis B vaccine in patients waiting for lung transplantation. Pharmacotherapy, 2003; 23(5) 555-60

9. Foster WQ, Murphy A, Vega DJ et al: Hepatitis B vaccination in heart transplant candidates. J Heart Lung Transplant, 2006; 25(1): 106-9

10. Danzinger-Isakov L, Kumar D: Guidelines for vaccination of solid organ transplant candidates and recipients. Am J Transplant, 2009; 9(Suppl.4): S258-62

11. Cornberg M, Protzer U, Petersen J et al: [Prophylaxis, diagnosis and therapy of hepatitis B virus infection - the German guideline]. Z Gastroenterol, 2011; 49(7): 871-930 [in German]

12. Chamorro $\mathrm{C}$, Aparicio $\mathrm{M}$ : Influence of anti-HBc positive organ donor in lung donor selection. Arch Bronconeumol, 2012; 48(9): 320-24

13. Joines RW, Blatter $M, A b r a h a m ~ B$ et al: A prospective, randomized, comparative US trial of a combination hepatitis $A$ and $B$ vaccine (Twinrix) with corresponding monovalent vaccines (Havrix and Engerix-B) in adults. Vaccine, 2001; 19(32): 4710-19

14. Shitrit AB, Kramer MR, Bakal I et al: Lamivudine prophylaxis for hepatitis $B$ virus infection after lung transplantation. Ann Thorac Surg, 2006; 81(5): 1851-52 